\title{
SEDIMENT SORTING AND BEACH MORPHOLOGY UNDER PLUNGING WAVE BREAKING
}

\author{
Adrián Pedrozo-Acuña ${ }^{1}$, Diana Resendiz ${ }^{1}$, Edgar Mendoza $^{1}$, Rodolfo Silva ${ }^{1}$ \\ ${ }^{1}$ Instituto de Ingeniería, Universidad Nacional Autónoma de México, Cd. Universitaria, 04510, México \\ apedrozoa@iingen.unam.mx; dresendizm@iingen.unam.mx; emendozab@iingen.unam.mx; \\ rsilvac@iingen.unam.mx;
}

\begin{abstract}
This paper presents an experimental investigation into the response of coarse-grained beaches under the action of plunging wave breaking. Beach profile results allowed the identification of three main morphological responses. These are: a beach profile which presented the generation of a clear step below the SWL; a beach shape that did not form any beach step; and a beach face which evolved a bar-like step. Additionally, high-resolution velocity measurements illustrate the prevailing hydrodynamic conditions in the surf-swash transition zone. These results were validated with ADV measurements collected at two cross-shore locations. Through Euler's equation the pressure field was associated to the total acceleration in the fluid, allowing a careful assessment of the contribution of each the acceleration terms to the resulting momentum balance. In the region close to the impact point, the magnitude of the local acceleration under the plunging waves is insignificant, while at the same location the role of advective terms cannot be overlooked. Results indicate the relevance of including advection processes for the accurate calculation of sediment transport under the action of plunging breakers across the nearshore zone.
\end{abstract}

Keywords: plunging breaking waves; advection; sediment sorting

\section{INTRODUCTION}

The morphological response of the beaches to a given wave climate is governed by nearshore hydrodynamics. Wave breaking and broken waves induce turbulent flows which stir up sediment, enabling transport by the mean flow and long and short waves (Baldock et al., 2010). In particular, the surf and swash zones play an important role in the behavior of sediment patterns, and therefore, exert a control in the erosive and accretive processes (Brocchini and Baldock, 2008).

The comprehensive understanding of the morphological response of a beach, however, requires an accurate determination of the water flow motions that take place in the surf zone and are transformed and interact within the swash zone (Masselink and Puleo, 2006). The lack of understanding on beach response to wave climate is ascribed to the strong unsteady flows, high turbulence levels, large sediment transport rates and rapid morphological changes that are present in the nearshore zone. In recent years, researchers have focused their attention on the explanation of the driving transport mechanisms in the surf/swash regions in a separate manner. Amongst the different processes that have been suggested as possible sources of the observed sediment transport asymmetry are: bottom friction (Raubenheimer et al., 2004; Cox et al. 2000), infiltration and exfiltration through the beach face (Butt et al. 2001; Turner 1995; Turner and Masselink 1998; Turner and Nielsen, 1997), acceleration asymmetry (Baldock and Hughes, 2006; Suzuki et al. 2010; Pedrozo-Acuña et al., 2011), bore collapse (Puleo et al. 2000; Jackson et al., 2004), backwash length (Butt and Russell, 1999) and sediment advection (Alsina et al. 2009). It is clear that all the aforementioned mechanisms have all a role to play in a resulting beach morphology, but the complexity relies in the elucidation of the relative importance of these processes along the beach

From all surf zone motions, plunging breakers have aroused a great deal of attention. This type of wave breaking is characterized by a sudden violent transition, which transforms the vortex motions into a turbulent bore, and produces an overturning of the wave (Chanson and Lee, 1997; Chanson et al., 2002), which leads to the generation of large quantities of turbulence. Research efforts looking at plunging wave breaking have concentrated on the investigation of the resulting velocity profile and turbulent fields under controlled conditions in the laboratory (e.g. Ting and Kirby, 1994, 1995). Most of these studies include features of plunging breakers in the outer region of the surf zone (e.g. Peregrine, 1983; Basco, 1985; and Battjes, 1988) but lack of the characterization of the morphodynamic feedback produced between waves and sediment. A recent study presented by Pedrozo-Acuña et al. (2008) hypothesized that under plunging waves both, the impulsive signature of the wave impact and the induced pressure gradient, were relevant for sediment stirring in the uprush phase of the flow. It was demonstrated that wave-impacts from plunging breakers are responsible for the observed onshore/offshore transport of sediment. 
Following these conclusions, Pedrozo-Acuña et al. (2010) demonstrated a complex vertical variation of the momentum balance under plunging waves through the combination of numerical simulations and laboratory data. Moreover, a recent experimental investigation indicated that for plunging waves in the swash, results point toward a significant role of the advective terms in the generation of pressure gradients (Pedrozo-Acuña et al., 2011). Thus, these results highlight the need of more research devoted to the investigation on the effects plunging wave breaking on beach morphology.

Hence, this study presents an integrated investigation into the response of coarse-grained beaches under the action of plunging wave breaking. These experimental results are used to enhance the understanding on how a given hydraulic regime is responsible of a particular beach response, including sediment sorting along the beach. This paper is organized as follows: Section 2 presents the aim of this investigation; Section 3 introduces the experimental setup, the bi-modal mixture selected for the sediments and the wave conditions; Section 4 resumes the results with regard to morphological changes, sediment sorting and the velocity field; Section 5 illustrates the diagnostic investigation of the momentum balance observed at different cross-shore locations along the beachface. Finally, conclusions are introduced in Section 6.

\section{AIM}

The aim of the present investigation is to examine under controlled conditions the momentum balance observed under plunging wave action, discussions will be drafted under the light of observed morphological response and sediment sorting along the beach profile.

\section{EXPERIMENTAL SETUP}

The experimental tests were carried out in a wave flume at the Coastal Engineering Laboratory of the Engineering Institute at UNAM. The flume has a length of $37 \mathrm{~m}$, a width of $0.8 \mathrm{~m}$, and a depth of $1.2 \mathrm{~m}$. The operating mean water depth is within the range 0.3 and $0.85 \mathrm{~m}$. The "beach" was installed at the end of the flume and consisted of impermeable slope of 1:5 of acrylic and aluminium, over which a bimodal mixture of sediments $(12 \mathrm{~cm}$ depth) was placed. The flume has a glass sidewall that facilitates recording by camera and visual observations of the wave transformation processes. Figure 1 presents the experimental setup at the flume for all the tests carried out in the investigation.

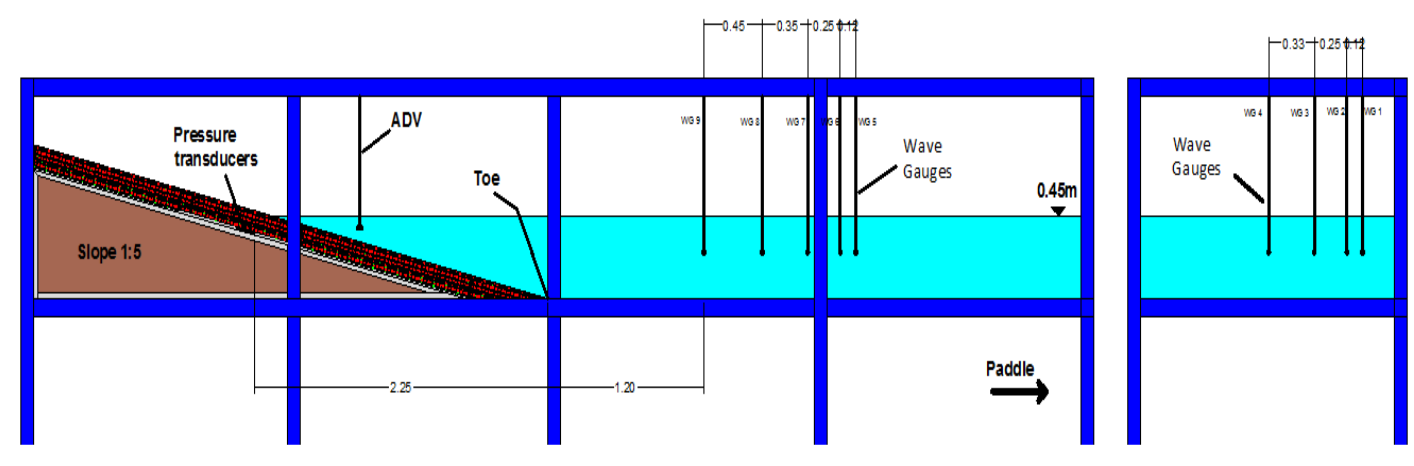

Figure 1. Experimental Setup

For all the tests, a total of 9 capacitance wave gauges (wg) were placed along the flume to record water surface elevations (see Table 1). Additionally, a set of 6 pressure transducers (PTs) high accuracy submersible level transmitters (type Acculevel) were deployed, and had a 0.1 bar range with the amplifiers set to $0 \mathrm{v} \sim 100$ mbar. The PTs measured water pressure transmitted through fluid or pressures transmitted through air. Table 2 shows the exact cross-shore location for these instruments. The PT locations were selected in order to cover the wave-impact region in the nearshore zone. The sampling frequency of all instruments was set at $100 \mathrm{~Hz}$. A first group of velocity measurements were carried out at one offshore location for all tests using an acoustic Doppler velocimeter for the laboratory (Vectrino, Nortek) sampling at $80 \mathrm{~Hz}$. 
Table 1. Wave gauge positions along the flume with respect to the wave paddle.

\begin{tabular}{|c|c|}
\hline Instrument & Cross-shore distance from toe (m) \\
\hline Wave gauge 1 & 1.2 \\
\hline Wave gauge 2 & 1.65 \\
\hline Wave gauge 3 & 2 \\
\hline Wave gauge 4 & 2.25 \\
\hline Wave gauge 5 & 2.37 \\
\hline Wave gauge 6 & 14.37 \\
\hline Wave gauge 7 & 14.72 \\
\hline Wave gauge 8 & 14.97 \\
\hline Wave gauge 9 & 15.09 \\
\hline
\end{tabular}

Table 2. Wave gauge positions along the flume with respect to the wave paddle.

\begin{tabular}{|c|c|}
\hline Instrument & Cross-shore distance from toe $(\mathrm{m})$ \\
\hline PT 1 & 2.250 \\
\hline PT 2 & 2.268 \\
\hline PT 3 & 2.286 \\
\hline PT 4 & 2.304 \\
\hline PT 5 & 2.322 \\
\hline PT 6 & 2.340 \\
\hline
\end{tabular}

The bimodal mixture of sediment was comprised by two sediment types. First, a coarse sediment defined as granules with a mean diameter of $3.6 \mathrm{~mm}$ and coloured in red was selected. Additionally, a coarse sand was employed with a mean diameter of $2.2 \mathrm{~mm}$ coloured in green. The mixture was built following a 50-50\% relationship, resulting in a mixture with a mean diameter of $2.6 \mathrm{~mm}$ and relative density of 2.6. Figure 2 illustrates the sediment distribution curve for the utilised mixture and the two sediment sizes.

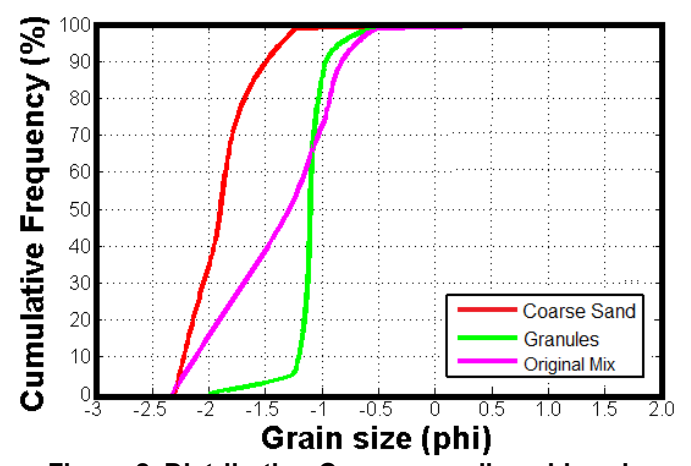

Figure 2. Distribution Curve according phi scale

The selected regular wave conditions (Table 2) correspond to plunging breakers on the 1:5 permeable beach slope. Different surf similarity parameters were tested by testing different combinations of wave height and period. The wave conditions were selected with the purpose of generating a strong waveimpact on the beach profile. For this, and following results presented by Pedrozo-Acuña et al. (2008) we employed the Iribarren number selecting values between 0.6 and 1.5 , where those closest to the 0.6 
value are expected to produce a more intense impact. The experiments consider two conditions: with low and high energy considering waves of 12 and $16 \mathrm{~cm}$ height and varying periods of $1,1.5$ and 2 seconds. The selected wave conditions are reported in Table 3.

Table 3. Selected wave conditions for each test to generate plunging breakers with hswl= $0.45 \mathrm{~m}$.

\begin{tabular}{|c|c|c|c|}
\hline Test No. & $\begin{array}{c}\mathrm{H} \\
{[\mathrm{cm}]}\end{array}$ & $\begin{array}{c}\mathrm{T} \\
{[\mathrm{s}]}\end{array}$ & $\boldsymbol{I r}=\frac{\tan \boldsymbol{\beta}}{\sqrt{\mathbf{H} / \mathbf{L}_{\boldsymbol{o}}}}$ \\
\hline $\mathrm{H} 12 \mathrm{~T} 10$ & 12 & 1 & 0.7214 \\
\hline $\mathrm{H} 12 \mathrm{~T} 15$ & 12 & 1.5 & 1.0821 \\
\hline $\mathrm{H} 12 \mathrm{~T} 20$ & 12 & 2 & 1.4428 \\
\hline $\mathrm{H} 16 \mathrm{~T} 10$ & 16 & 1 & 0.6248 \\
\hline $\mathrm{H} 16 \mathrm{~T} 15$ & 16 & 1.5 & 0.9371 \\
\hline $\mathrm{H} 16 \mathrm{~T} 20$ & 16 & 2.0 & 1.2495 \\
\hline
\end{tabular}

Measurements of hydrodynamic variables (e.g. pressure, velocities and water surface) were carried out for each wave condition. Morphological changes along the beach profile were generated by the action of the waves, which were run for 3 hours in order to attain equilibrium. Therefore, the wave condition was divided in three batches of 60 minutes. To register the evolution in time of the beach profile, measurements were carried out at the beginning and at the end of each batch. Additionally, following Rivillas-Ospina et al. (2012), the velocity field in the surf/swash transition was obtained by means of a no-intrusive technique known as Bubble Image Velocimetry (BIV). In order to validate results obtained with this technique, point velocity measurements (at different locations) by means of an Acoustic Doppler Velocimeter (ADV) were also carried out for selected tests. Finally, in order to report sediment sorting on the beach profile sediment samples were taken at 6 different cross-shore locations along the beach profile.

The BIV method was employed to characterise flow motions under plunging waves propagating over the permeable beach. Continuous video recording was carried out at a rate of $1077 \mathrm{fps}$ with a resolution of $1056 \times 512$ pixels for a single wave period and all the tests reported in Table 3 . The aperture of the camera was set with an f-number between 2.8 and 4.0. A trigger pulse was sent to the data acquisition system at the end of the recording. The camera was mounted perpendicular to the direction of the flow in front of the glass side wall of the flume.For the setup of the image velocimetry method, a high-speed digital video camera (Fastec HighSpec 1) was employed together with back lighting provided by two Fresnel lights $(650 \mathrm{~W})$ placed at both corners of the domain of interest. In addition, an open face light $(650 \mathrm{~W})$ was placed above the impermeable beach slope. The camera and lighting arrangement used for the shadowgraph technique is illustrated in Figure 3.

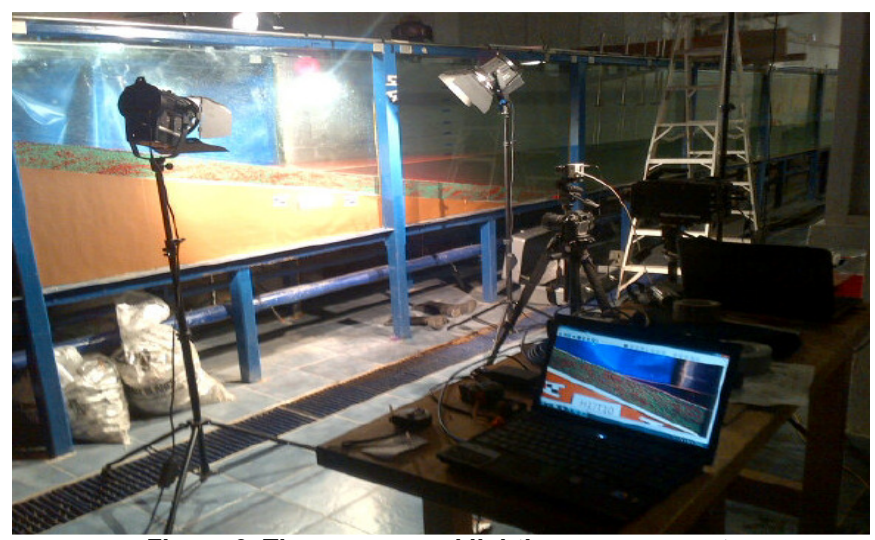

Figure 3. The camera and lighting arrangement 


\section{RESULTS}

\subsection{Morphological changes under plunging waves}

Figure 4 presents the results associated to the equilibrium beach profiles observed for the elected wave conditions. Two morphological responses are identified, these are associated to the wave period of the incident wave. For instance, longer waves ( $\mathrm{T}=1.5$ and $2 \mathrm{~s})$ present a beach profile with the generation of a clear step below the SWL, while short waves $(\mathrm{T}=1 \mathrm{~s})$ illustrate a beach shape that did not form any beach step. Instead, a bar-type profile is found. The intermediate case given by $\mathrm{T}=1.5 \mathrm{~s}$, presents a beach profile characterised by a bar-like step with little erosion on the beachface.

These morphological responses can be differentiated using the value of surf similarity parameter for each wave condition. In these examples, short period waves $(T=1 \mathrm{~s})$ are related to more intense wave-impacts on the beachface. Evidence of this forcing is illustrated in the clear excavation that is present in a region close to the SWL. Sediment in this zone is stirred by the wave-impact to be transported and deposited in relation to the balance of nearshore processes (e.g. infiltration and undertow). For instance, it is evident that some of the sediments are transported during the run-up phase towards the upper part of the beach profile (some sediment is indeed deposited to form a small berm). In contrast, a process that acts in the opposite direction is the backwash flow, which in average generates an undertow that may be contributing to the generation of the bar.

In the case of longer wave periods, the strength of the wave-impact is not as strong as in the short period waves; indeed, a wider cross-shore region is under the action of the waves. In all the wave periods studied, the observed morphological change is only intensified by the action of a higher wave height. All the morphological features observed for a $\mathrm{H}=12 \mathrm{~cm}$ are magnified by wave tests with $\mathrm{H}=16 \mathrm{~cm}$.
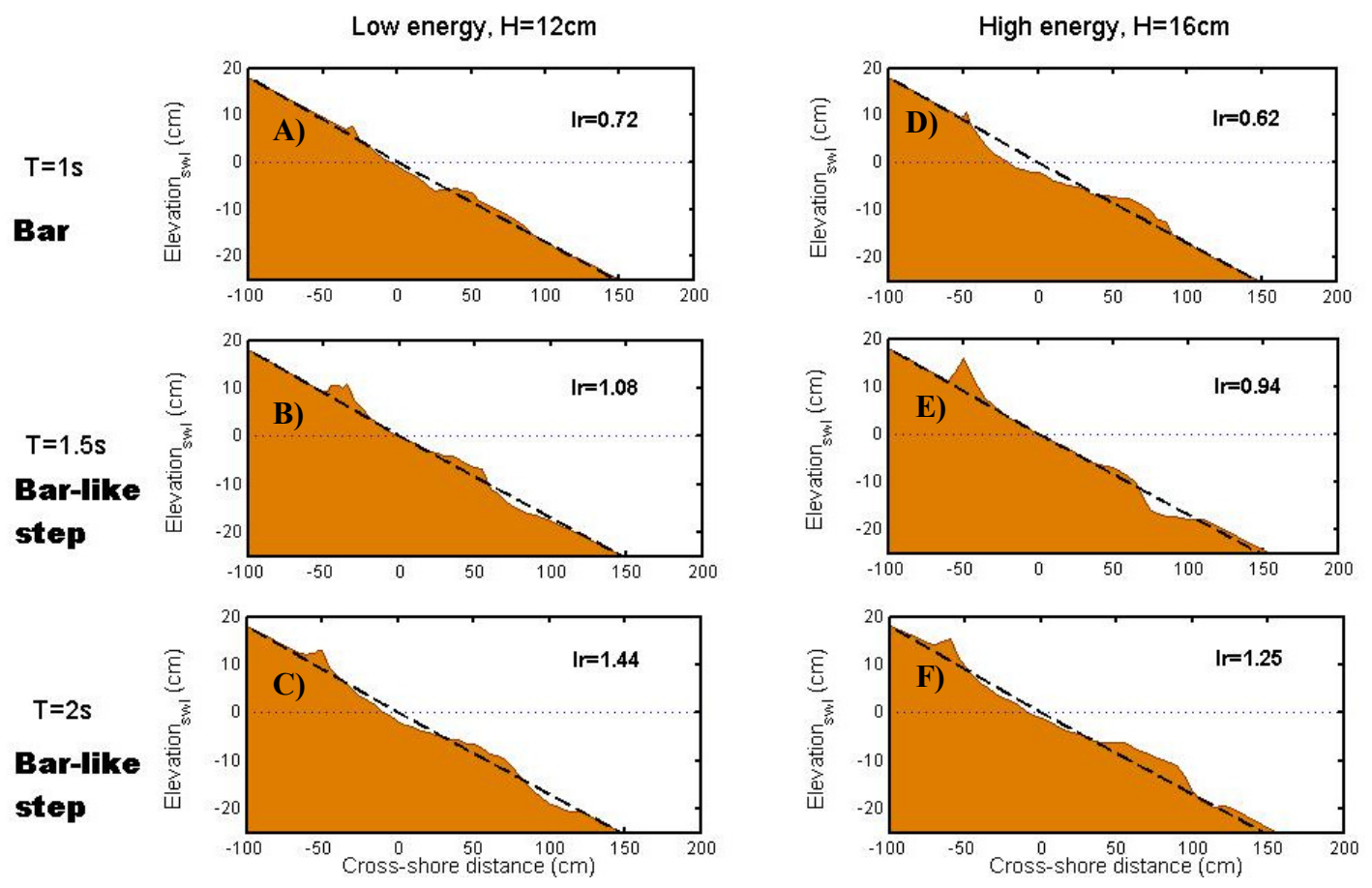

Figure 4. Morphological profile after an equilibrium condition. A) Test H12T10, B) Test H12T15, C)Test H12T20, D) Test H16T10, E) Test H16T15, F) Test H16T20.

\subsection{Sediment sorting}

Sediment sorting along the beach profile was also investigated through the analysis of sediment samples taken once the beach profile reached an equilibrium state, at the end of each test. This was done in order to observe the sediment re-distribution by the wave action. The sampling points were 
selected along morphological features on the profile such as the berm, the SWL and the bar. The comparison of the initial sediment distribution against that observed after the wave action, may provide some evidences on the processes that were important in generating the beach response.

Figure 5 introduces the results for the low energy wave condition defined by a wave height of 12 $\mathrm{cm}$. Different rows present photographic evidence of the equilibrium beach profile along with the sediment distribution curve at the indicated locations on the profile by the arrows. Top row a) introduces results for a wave period of $1.0 \mathrm{~s}$, while rows b) and c) illustrate the same results for wave periods of 1.5 and $2 \mathrm{~s}$, respectively.

In general, the wave period length is determinant in the distribution of sediments along the beachface. Shorter waves tend not to rework the sediments, this is observed through the shapes of the sediment distribution curve at different cross-shore locations, which do not show much variation with respect the initial distribution. In contrast, for longer wave period waves a clear distribution of sediments is identified at the selected positions. An armouring of the beach face is reported at both the bar and the SWL, whereas at the berm finer sediment is deposited. For the three cases presented, the observed sediment sorting is classified as very well and well sorted.
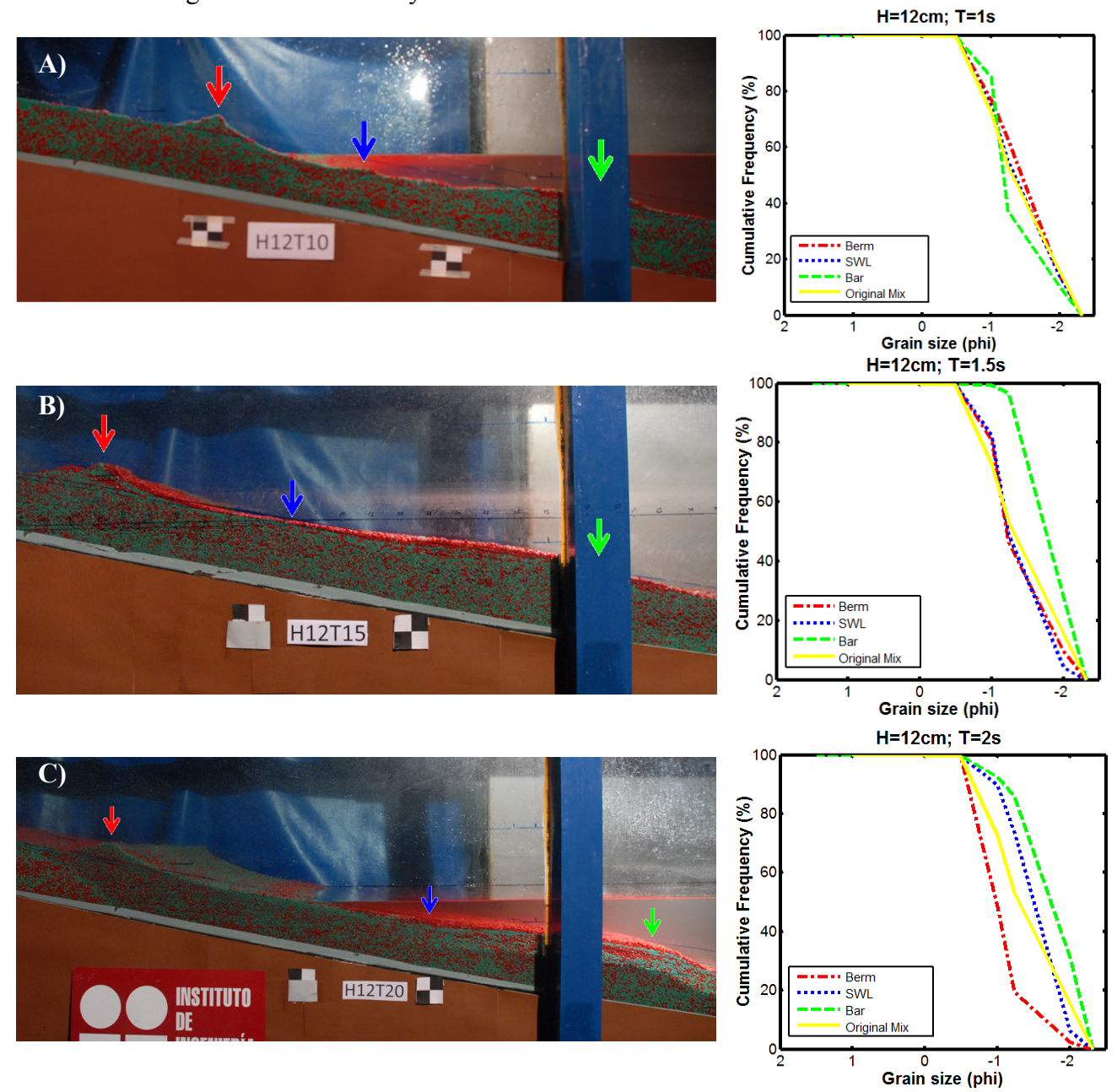

Figure 5. Left panels show a beach profile photography and right panels the sediment distribution curve for the position of the berm, shoreface and bar/bar-step. A) Test H12T10, B) Test H12T15, C) H12T2O.

On the other hand, Figure 6 shows results for the same wave periods but considering a wave height of $16 \mathrm{~cm}$. In this case, the re-distribution of the sediment along the beach is clearer in all cases. Even for the short period wave, where an armouring of the step evident along with deposition of finer 
sediments at the berm. For the wave period of $1.5 \mathrm{~s}$, an armouring of the beach profile as a whole is reported, in all three locations the sediment distribution curve indicates the presence of coarser sediment with respect to the initial mixture. Results for the $2 \mathrm{~s}$ wave period report a similar beach response in terms of the morphology, but the beach step appears further offshore with respect to shorter wave periods. The sediment distribution curve indicates the deposition of coarser sediments at the beach step, whereas finer sediments are placed at the top of the profile generating a berm. Results indicate the greater tendency of coarser sediments to be deposited at the beach step, an observation that has also been reported in coarse-grained beaches in the field (Austin and Buscombe, 2008).
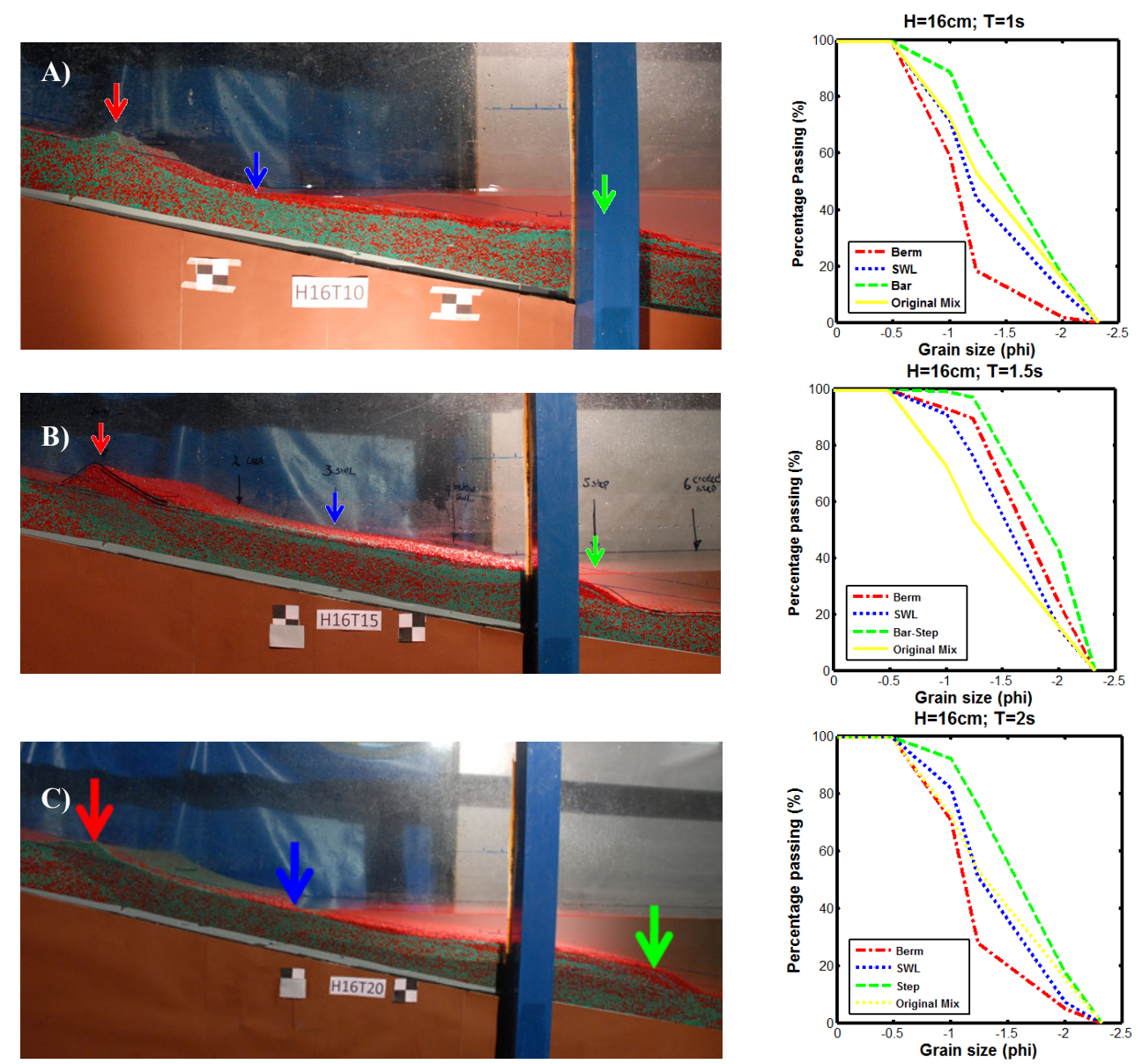

Figure 6. Left panels show a beach profile pictures and right panels the sediment distribution curve for the position of the berm, shoreface and bar/bar-step. A) Test H16T10, B) Test H16T15, C) H16T20.

\subsection{Velocity field}

The measurement of velocity fields in breaking waves has been of great interest to various researchers. This study uses the Bubble Image Velocimetry (BIV) technique to characterise the velocity field (Ryu et al. 2005; Ryu et al. 2007). As reported by Rivillas-Ospina et al. (2012) this technique is able to reveal the flow pattern in plunging waves impinging on impermeable sloping beds. A colour high-speed digital video camera was employed together with back lighting provided by two Fresnel lights $(650 \mathrm{~W})$, placed at both corners of the domain of interest. Continuous video recording was carried out at a rate of $1077 \mathrm{fps}$ with a resolution of 1920x1080 pixels for a single wave period. The interrogation window was set to 32 × 32 pixels, in which a Minimum Quadratic Difference algorithm was applied to estimate pattern displacements and flow velocities. The BIV technique was applied for all wave conditions once the beach profile reached an equilibrium shape. 
Figure 7 illustrates the BIV derived velocity fields for a plunging wave defined by $\mathrm{H}=12 \mathrm{~cm}$ and $\mathrm{T}=1.0 \mathrm{~s}$. Right panels present the photographic snapshots captured with the high speed camera, while left panels illustrate for the same instant, the BIV derived horizontal velocity field. These results demonstrate the complexity of the hydrodynamics resulting from the action of a plunging wave on a beach. In this figure, positive values are directed onshore and negative values are directed offshore. Clearly, higher onshore velocities are associated to the wave-impact process on the shoreface. The flow separation is also identified in the left panel of the fourth row. Additionally, a complex vertical structure of the flow is revealed, which points towards the significance of advective terms in the momentum balance.
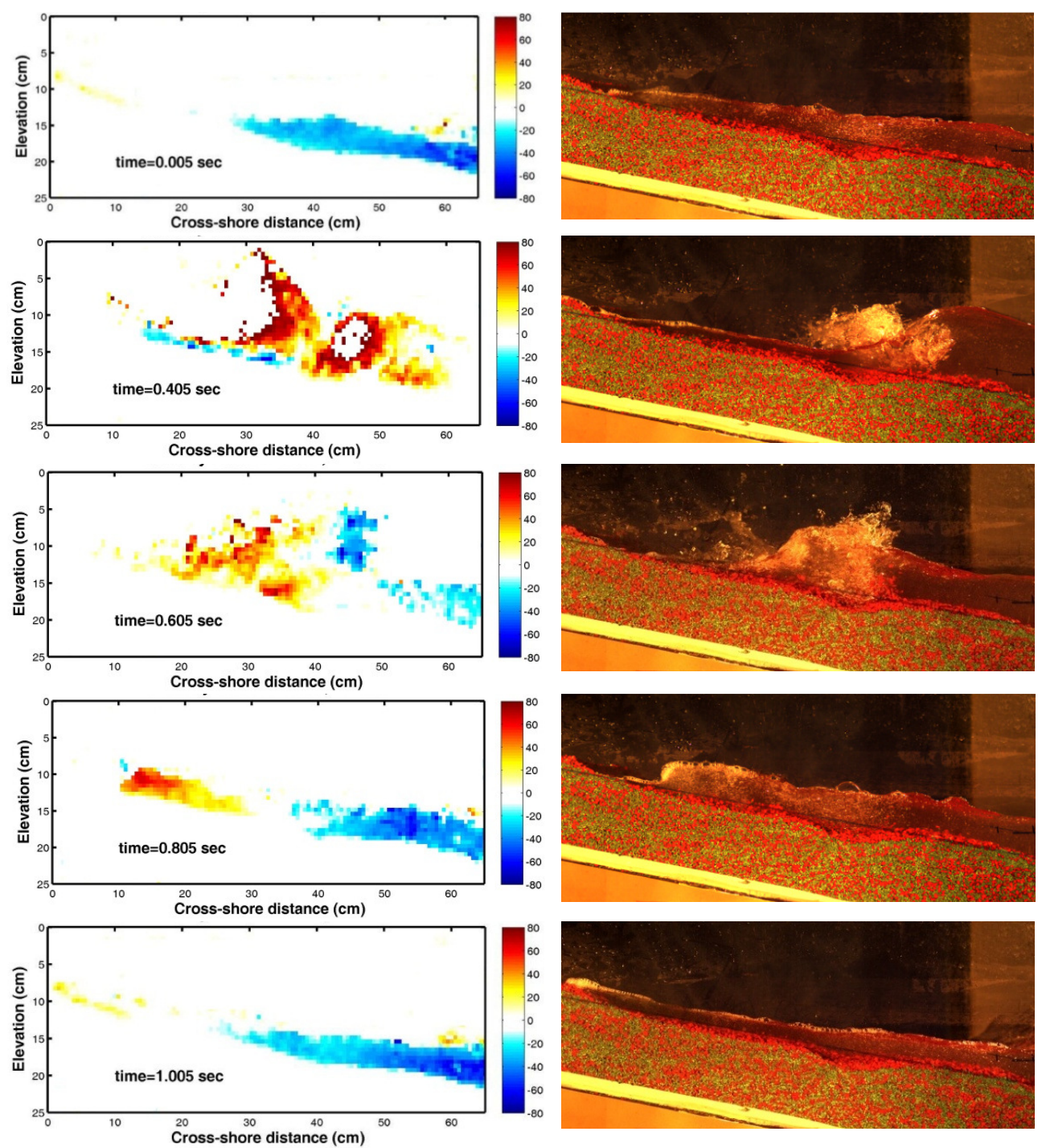

Figure 7. Snapshots of a plunging wave $(H=0.12 \mathrm{~m} ; \mathrm{T}=1.0 \mathrm{~s})$ travelling on the permeable slope (right panels) and BIV derived horizontal velocity fields in $\mathrm{cm} / \mathrm{s}$ (left panels).

Time series of horizontal velocity derived from the BIV technique were also compared against measurements obtained with an Acoustic Doppler Velocimeter (ADV). Panel a) of Figure 8 illustrates the location of the points that were selected for this comparison. Two points were chosen identified by the SWL and the bar location. Overall, as it is shown in panels b) and c), good agreement is found at both cross-shore positions. The red dotted line indicates the BIV derived velocities and blue solid those 
obtained by means of the ADV. These results provide confidence in the utilisation of the BIV derived velocities for an assessment of the momentum balance along the beach profile.
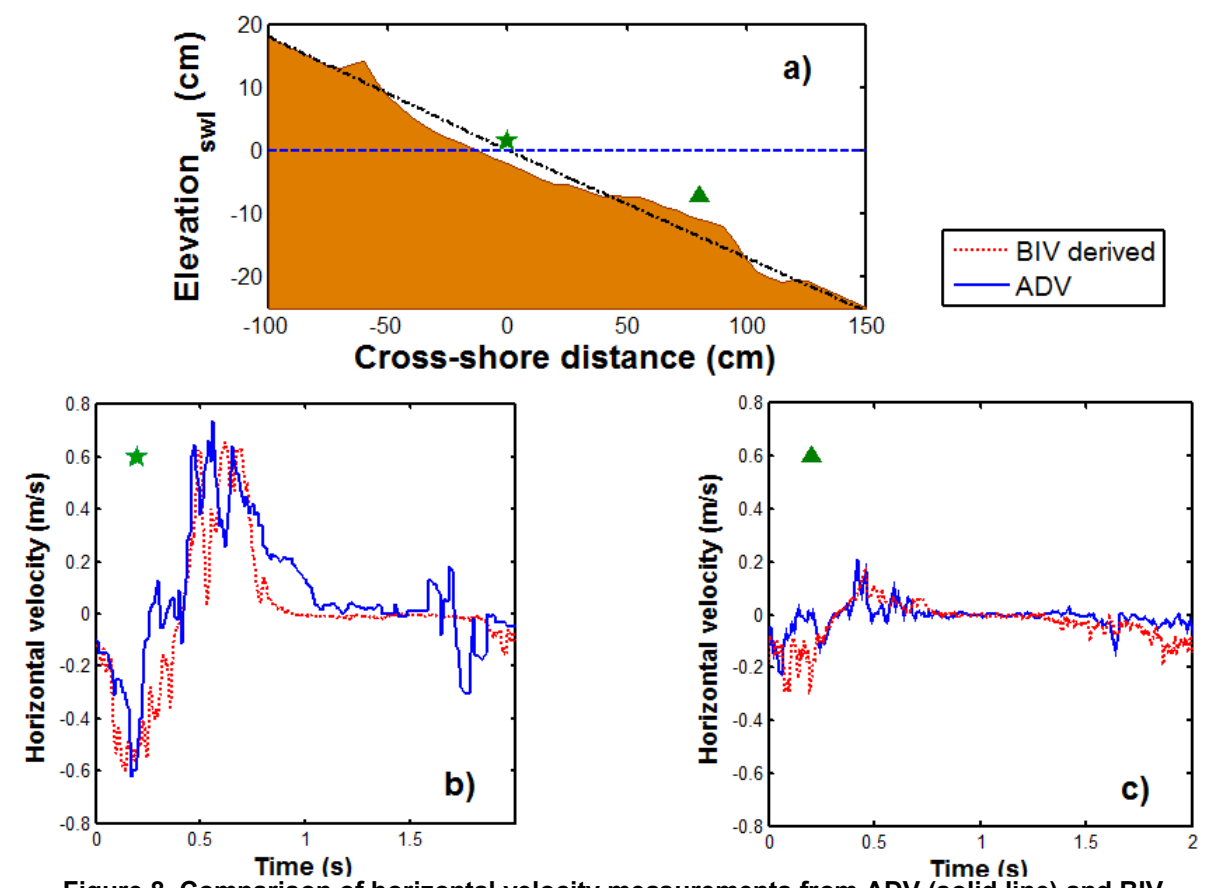

Figure 8. Comparison of horizontal velocity measurements from ADV (solid line) and BIV (dots). Panel a: illustrate the position of the point of analysis; Panel b: illustrate a point of analysis near swl; Panel b: illustrate point of analysis over the bar.

\section{MOMENTUM BALANCE}

As a starting point, the momentum balance is approximated using Euler's equation (e.g. Stansby and Feng, 2005; Pedrozo-Acuña et al. 2010), where we neglect the turbulence contribution as follows

$$
\rho \frac{D \mathbf{v}}{D t}+\nabla P=0
$$

where $\mathbf{v}=(\bar{u}, \bar{w})$ represents the mean flow velocity in both horizontal and vertical directions, $\rho$ is the fluid density, $P$ is the mean pressure. Assuming the validity of equation (1), any changes in the pressure will be a result of the total acceleration in the fluid. The total acceleration is the addition of the local acceleration plus the advective acceleration and can be written as:

$$
\frac{D \mathbf{v}}{D t}=\frac{\partial \mathbf{v}}{\partial t}+\mathbf{v} \cdot \nabla \mathbf{v}
$$

Expanding the products and gradients Equation (2), this can also be decomposed in both horizontal and vertical directions of total acceleration which are expressed as

$$
\frac{D \mathbf{v}}{D t}=\left\{\begin{array}{lr}
\frac{\partial \bar{u}}{\partial t}+\bar{u} \frac{\partial \bar{u}}{\partial x}+\bar{w} \frac{\partial \bar{u}}{\partial z} & \text { horizontal } \\
\frac{\partial \bar{w}}{\partial t}+\bar{u} \frac{\partial \bar{w}}{\partial x}+\bar{w} \frac{\partial \bar{w}}{\partial z} & \text { vertical }
\end{array}\right.
$$


The horizontal component of equation (3) is here evaluated in order to investigate the role of each of the terms in the resulting momentum balance under plunging wave breaking. For this, BIV derived velocity fields are utilised to calculate these quantities. The selected test conditions for this analysis correspond to $\mathrm{H}=16 \mathrm{~cm}$ and $\mathrm{T}=1.0 \mathrm{~s}$.

Three different cross-shore locations on the shoreface are investigated. Top panel of Figure 9 shows the snapshot of the plunging wave impinging on the beach, along with the location of the selected points of analysis. Middle row panels introduce BIV-derived time series of horizontal and vertical velocities at these three locations, these are identified with blue and red lines, respectively. Additionally, it is shown that both velocity components are significant at the point identified as Point 1 , which is the closest to the region where the wave-impact takes place. In comparison, the magnitude of both components at Points 2 and 3, is smaller. This is especially true for the vertical velocity, which illustrates a very small contribution at these locations. Similarly, bottom row panels illustrate the temporal variation of the local acceleration (blue line) and the advection terms horizontal (green line) and vertical (red line) at these same locations. The momentum balance, expressed as the sum of these quantities is also depicted by the discontinuous black line. Notably, at the three points of analysis the contribution of the local acceleration to the momentum balance is negligible. This results may indicate that for plunging wave breaking, the role of local acceleration is not significant. In contrast, in the neighbouring region of the impact point (1 and 2) the contribution of horizontal and vertical advective terms cannot be negligible. Moreover, at Point 1 , the momentum balance cannot be explained without considering their individual contribution. This result confirms a complex spatio-temporal evolution of the momentum balance under plunging wave breaking.
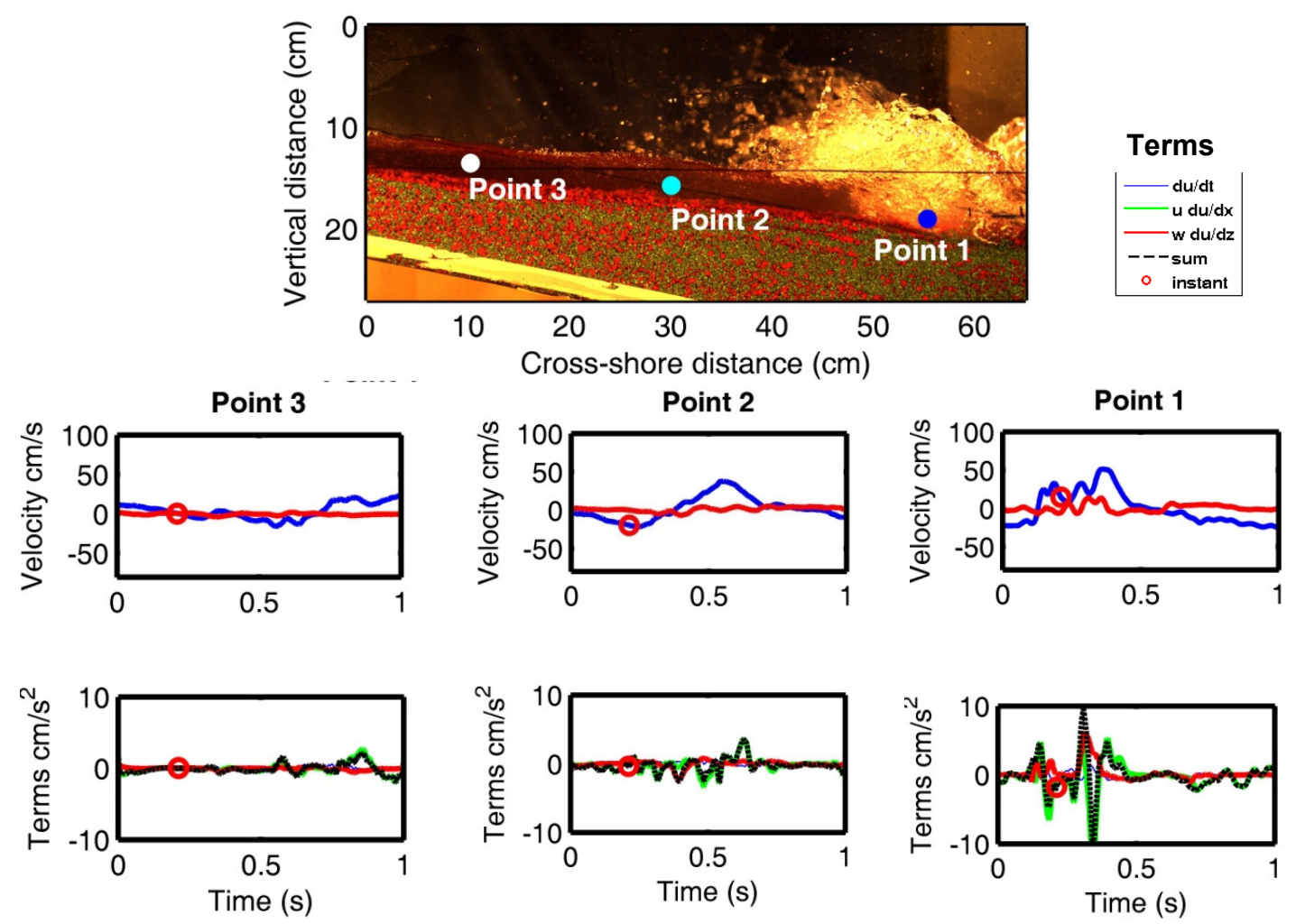

Figure 9. Test $\mathrm{H}=0.16 \mathrm{~m}, \mathrm{~T}=1 \mathrm{~s}$. Top panels illustrate the points of evaluation. Middle panels show velocities vertical (blue) and horizontal (red); Bottom panels show advective terms (horizontal in gree, vertical in red), local terms (blue) and the sum (gray).

The observed spatio-temporal variability of the momentum balance, highlights the need of more investigation in the nearshore area, considering the surf and swash zones as a whole. These 
experimental results are in accordance with conclusions put forward in a numerical study by PedrozoAcuña et al. (2010), whom pointed out that in the case of plunging wave breaking the local acceleration does not completely explain the pressure gradient and advective terms cannot be neglected. The results highlight the relevance of including advection processes for the accurate calculation of sediment transport under plunging breakers across the nearshore zone.

\section{CONCLUSIONS}

This investigation has presented laboratory observations of the spatio-temporal evolution of beach morphology, sediment sorting and momentum balance induced by the action of plunging breakers across the nearshore zone. Experimental results allowed the identification of three beach responses under the action of plunging wave breaking. These are: a beach profile which presented the generation of a clear step below the SWL; a beach shape that did not form any beach step; and a beach face which evolved a bar-like step. The morphological responses were differentiated with the value of surf similarity parameter defined in each wave condition. With regards to the sediment sorting results indicated that coarse material was generally deposited in morphological features close to the breaking point (bar or bar-step) and also beachface armouring was observed.

High-resolution measurements velocity fields under plunging breakers were presented for several wave conditions on a 1:5 slope. The 2DV velocity field was determined by the application of a Bubble Image Velocimetry (BIV) technique, which was validated with velocity time series collected with an ADV instrument. BIV derived velocities were utilised as a tool for the investigation of hydraulic regimes responsible of generating different beach responses and sediment sorting in the laboratory. Through Euler's equation the pressure field was associated to the total acceleration in the fluid, enabling an assessment of the contribution of each of its terms to the resulting pressure field. The diagnosis was carried out with the aim of identifying the momentum terms which contribute to the generation of sediment mobilisation and transport. It was found that in the region close to the impact point, the magnitude of the local acceleration under the plunging waves is insignificant, especially when compared to that of the advective terms. It was shown that under the action of plunging breakers a delicate balance between physical processes is present and determines the morphological response of the beach. The results here presented, point towards the relevance of including advection processes for the accurate calculation of sediment transport under plunging breakers across the nearshore zone.

\section{ACKNOWLEDGMENTS}

The research was supported in part by research grants from the National Autonomous University of Mexico (PAPIIT IN106610) and the National Council of Science and Technology in Mexico (CONACYT) Project number SEP-SEB 167003. We would also like to thank the following for their assistance with the laboratory work described in this paper: César Gutiérrez Valencia, Irving J. Álvarez, Miguel A. Laverde, Juan P. Rodríguez, Jesús Pinedo, Alejandro Bustos, Alejandro Ruíz, Carlos Armenta and Iván García.

\section{REFERENCES}

Alsina, J. M., Falchetti, S., Baldock T.E., 2009. Measurements and modelling of the advection of suspended sediment in the swash zone by solitary waves Coastal Engineering, 56 (5-6), pp. 621631

Austin, M.J., and Buscombe, D. 2008. Morphological Change and Sediment Dynamics of the Beach Step on a Macrotidal Gravel Beach. Marine Geology 249, 167-183. doi:10.1016/j.margeo.2007.11.008

Baldock, T.E., Hughes, M.G., 2006. Field observations of instantaneous water slopes and horizontal pressure gradient in the swash-zone. Continental Shelf Research, 26(5), 574-588.

Baldock, T.E., Manoonvoravong, P., Pham, K.S., 2010. Sediment transport and beach morphodynamics induced by free long waves, bound long waves and wave groups. Coastal Engineering, 57(10), 898-916.

Basco, D.R., 1985. A qualitative description of wave breaking. J. Waterw. Port Coastal Ocean Eng. ASCE, 111: 171-188. 
Battjes, J.A., 1988. Surf-zone dynamics. Annu. Rev. Fluid Mech., 20: 257-293.

Butt, T., Russell, P. 1999. Suspended sediment transport mechanisms in high-energy swash, Marine Geology, 161 (2-4), pp. 361-375.

Butt, T., Russell, P. and Turner, I., 2001. The influence of swash infiltration/exfiltration on beach face sediment transport: onshore or offshore? Coastal Engineering, 42: 35-52.

Brocchini, M., Baldock, T.E., 2008. Recent advances in modelling swash zone dynamics: Influence of Surf-Swash interaction on nearshore hydrodynamics and morphodynamics. Reviews of Geophysics, 46, RG3003. doi:10.1029/2006RG000215

Chanson, H., Lee, J.F., 1997. Plunging jet characteristics of plunging breakers. Coast. Eng. 31, 125141.

Chanson, H., Aoki, S., Maruyama, M., 2002. Unsteady air bubble entrainment and detrainment at a plunging breaker: dominant time scales and similarity of water level variations. Coast. Eng. 46, 139-157.

Cox, D.T., Hobensack, W. and Sukumaran, A., 2000. Bottom stress in the inner surf and swash zone. In: B. Edge (Editor), 27th International Conference on Coastal Engineering. ASCE, Sidney, Australia, pp. 108-119.

Jackson, N.L., Masselink, G., Nordstorm, K.F., 2004. The role of bore collapse and local shear stresses on the spatial distribution of sediment load in the uprush of an intermediate state beach. Marine Geology, 203, 109-118.

Masselink, G., Puleo, J.A., 2006, Swash zone morphodynamics, Continental Shelf Research, 26, 661680.

Pedrozo-Acuña, A., Simmonds, D.J. and Reeve, D.E., 2008. Wave-impact characteristics of plunging breakers acting on gravel beaches. Marine Geology, 253(1-2): 26-35.

Pedrozo-Acuña, A., Torres-Freyermuth, A., Zou, Q., Hsu, T.-J., Reeve, D.E., 2010. Diagnostic modelling of impulsive pressures induced by plunging breakers impinging on gravel beaches, Coastal Engineering, Vol.57, No.3, 252-266.

Pedrozo-Acuña, A., Ruiz de Alegría-Arzaburu, A., Torres-Freyermuth, A., Mendoza, E., Silva R., 2011. Laboratory investigation of pressure gradients induced by plunging breakers. Coastal Engineering, Vol.58, Elsevier, pp. 722-238, doi:10.1016/j.coastaleng.2011.03.013.

Peregrine, D.H., 1983. Breaking waves on beaches. Annu. Rev. Fluid Mech., 15: 149-178.

Puleo, J.A., Beach, R.A., Holman, R.A. and Allen, J.S., 2000. Swash zone sediment suspension and transport and the importance of bore-generated turbulence. Journal of Geophysical Research, 105(C7): 17021-17044.

Raubenheimer, B., Elgar, S. and Guza, R.T., 2004. Observations of swash zone velocities: A note on friction coefficients. Journal of Geophysical Research, 109(C01027).

Rivillas-Ospina, G.D., Pedrozo-Acuña, A., Silva R., Torres-Freyermuth, A., Gutiérrez, C., 2012. Estimation of the velocity field induced by plunging breakers in the surf and swash zones. Experiments in Fluids, doi: 10.1007/s00348-011-1208-x.

Ryu, Y., Chang, K.A., Lim, H.J., 2005. Use of bubble image velocimetry for measurement of plunging wave impinging on structure and associated greenwater. Measurement Science and Technology 16, 1945-1953.

Ryu Y, Chang K-A, Mercier R, 2007. Runup and green water velocities due to breaking wave impinging and overtopping. Exp Fluids 43:555-567

Stansby, P. and Feng, T. 2005. Kinematics and depth-integrated terms in the surf zone waves from laboratory measurement. J. Fluid Mech., 529, 279-310.

Suzuki, T., Shin, S., Cox, D.T., Mori, N., 2010, Spatio-temporal characteristics of near-bed pressure gradients on a barred beach. Journal of Waterway, Port, Coastal, and Ocean Engineering, doi:10.1061/(ASCE)WW.1943-5460.0000055.

Ting, F.C.K. and Kirby, J.T., 1994. Observation of undertow and turbulence in a laboratory surf zone. Coastal Eng., 24(1-2): 51-80.

Ting, F.C.K. and Kirby, J.T., 1995. Dynamics of surf-zone turbulence in a strong plunging breaker. Coastal Eng., 24: 177-204.

Turner, I.L., 1995. Simulating the influence of groundwater seepage sediment on sediment transported by the sweep of the swash zone across macro-tidal beaches. Marine Geology, 125(1-2): 153-174.

Turner, I.L. and Masselink, G., 1998. Swash infiltration-exfiltration and sediment transport. Journal of Geophysical Research, 103(C13): 30813-30824.

Turner, I.L. and Nielsen, P., 1997. Rapid watertable fluctuations within the beachface: implications for swash zone sediment mobility? Coastal Engineering(32): 45-59. 